\title{
Study of the Design of Data Acquisition and Analysis Systems for Multi-purpose Regional Energy Systems
}

\author{
Hansang Lee*, Dong-Hee Yoon*, Gilsoo Jang ${ }^{\dagger}$, Jong-Keun Park** and Goon-Cherl Park***
}

\begin{abstract}
Recently, the smart grid has become a hot issue and interest in related power sources have increased accordingly. The implementation of a smart grid can enable many generation resources to be linked to the power system, including small-scale reactors for the purpose of co-generation. Research on small-scale reactors is being carried out all over the world. Similarly, Korea is also conducting research on multi-purpose regional energy systems using nuclear energy. This paper proposes a real-time data acquisition and analysis system for small-scale reactors, and is known as the REX-10 (Regional Energy rX 10 MVA). This analysis requires real-time simulations for the power system since it needs data communication with a remote REX-10. A RTDS (Real Time Digital Simulator) has been used for the simulation, and a SCADA/HMI system interfaced with the RTDS is proposed for the purpose of monitoring and control of the regional energy system.
\end{abstract}

Keywords: Small-scale reactor, Power system dynamic performance, REX-10 system, Real time simulator, SCADA system, HMI

\section{Introduction}

Recently, Korea has begun to consider the implementation of distributed energy sources based on small reactors as part of its $\mathrm{CO}_{2}$ emission reduction program. This type of generation is suitable for a small micro-grid or a power system on a small island. Since Korea has many small islands, a small-scale reactor can be used as a stable base generator which can supply electric power and heat for the local area. In order to validate the use the small reactor on a small electrically-isolated island, the economic and dynamic analysis of the implementation needs to be performed.

This paper proposes an integrated system which consists of a real-time simulator, a SCADA (Supervisory Control and Data Acquisition) system, a small reactor, IEDs and an HMI (Human-Machine Interface). This integrated system is required for analysis and monitoring of power systems that include small reactors. This paper deals with RSCAD/ RTDS electrical models of small-scale reactors and power systems. The connection between the RTDS and the SCADA system has been implemented to visualize the electrical data and control actions.

\section{REX-10 System [1-2]}

\subsection{Small-scale Reactor and Co-generation System}

Generally, an integrated modular reactor pilot plant sys-

\footnotetext{
Corresponding Author: Dept. of Electrical Engineering, Korea University, Korea. (gjang@korea.ac.kr)

* Dept. of Electrical Engineering, Korea University, Korea. (hansang80, dongace@korea.ac.kr)

** Dept. of Electrical and computer Engineering, Seoul National University, Korea. (parkjk@snu.ac.kr)

*** Dept. of Nuclear Engineering, Seoul National University, Korea. (parkgc@snu.ac.kr)

Received : August 18, 2009; Accepted : October 1, 2009
}

tem is described as a SMART system (also referred to as SMART by itself). For implementation of this SMART system in local power systems, the proper pressure and capacity required for stable operation should be defined. In this paper, in order to validate the operability of a small nuclear power plant, a study of the SMART system, which is designated as 'REX-10 (Regional Energy rX 10 MVA)', for a regional energy supply is conducted. The requirements of the REX-10 are as follows:

- The REX-10 must be stable. It is specially designed for installation only in an underground level because of local demands.

- The amount of radioactive waste of the REX-10 must be minimal. As radioactive waste decreases, the operation life of the REX-10 increases. In this study, the REX-10's life expectancy is over 10 years.

- The REX-10 must be economically feasible.

The REX-10 is used as a co-generation device, and which refers to the combined production of electricity and heat in an energy conversion facility. Generally, cogeneration technologies are available for the combined production of electricity and heat, and can use fossil or nuclear energy sources, as well as biomass. Co-generation is meaningful for applications where there is a large and continuous demand for heat close to the co-generation facility. Since transmitting electricity from the mainland to a remote island is not only uneconomical but also demanding, co-generation is preferable to meet an island's power system's energy demands [3]-[4].

In this study, radioactive wastes and emissions are not considered. Even though co-generation systems have a more diluted environmental impact than large thermal power plants, the danger of nuclear power to the environment should not be neglected. 


\subsection{Description of REX-10}

REX-10 is an integral type PWR (Pressurized-water reactor) as shown in Fig. 1. The integral reactor concepts are characterized so that the entire primary systems, such as the core, pumps, main heat exchangers (steam generators) and pressurizers, etc., are arranged in a single pressure vessel. Thus, a large break LOCA (Loss-of-Coolant Accident) can be excluded. Unlike SMART, REX-10 is designed to remove heat from nuclear fuel by natural circulation and to be operated with low system parameters compared with traditional PWR. The REX-10 is operated with full power natural circulation cooling at all power levels so that primary circulating pumps can be eliminated. In order to increase the natural circulation capacity, there is a long riser in the upper part of the core. In addition, the passive safety method was enhanced by adopting a self-pressurized builtin steam-gas pressurizer, and nitrogen gas is used for initial pressurization. Additional pressure is generated by steam from the primary coolant. The steam generator is a type of helical-coiled tube bundle based on SMART. In addition, the integral type of helical-coiled steam generator is also considered. The proliferation-resistance of the fuel is a very important feature of the REX-10. Thus, the thorium fuel is the best candidate fuel for small power reactors.

The detailed design parameters of the REX-10 are determined considering system pressure, total thermal power

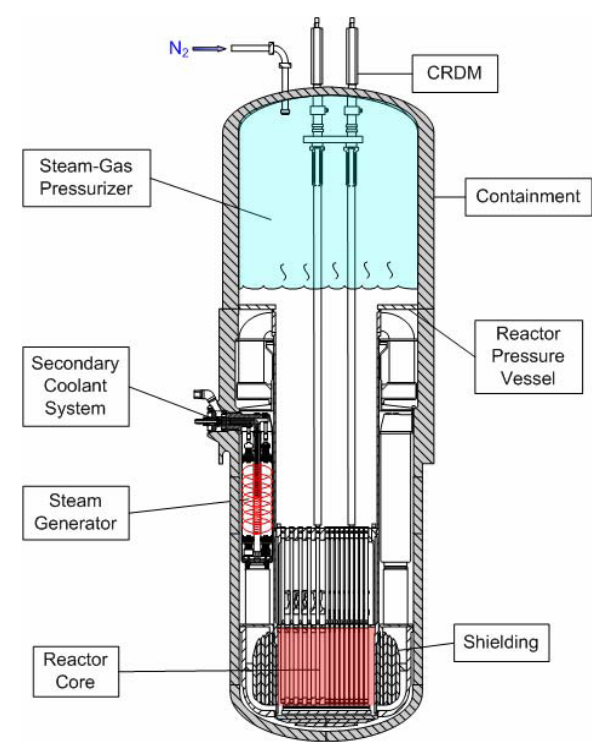

Fig. 1. A schematic diagram of the REX-10.

Table 1. Design Parameters of REX-10

\begin{tabular}{c|c|c}
\hline \multirow{4}{*}{$\begin{array}{c}\text { Primary } \\
\text { circuit }\end{array}$} & Cooling mode & Natural circulation \\
\cline { 2 - 3 } & Coolant flow rate & $64.9 \mathrm{~kg} / \mathrm{s}$ \\
\cline { 2 - 3 } & Core inlet temperature & $165^{\circ} \mathrm{C}$ \\
\cline { 2 - 3 } & Core outlet temperature & $200^{\circ} \mathrm{C}$ \\
\hline \multirow{4}{*}{$\begin{array}{c}\text { Secondary } \\
\text { circuit }\end{array}$} & Type & Helical-coiled once-through \\
\cline { 2 - 3 } & Steam temperature & $198.3^{\circ} \mathrm{C}$ \\
\cline { 2 - 3 } & Steam pressure & $1.5 \mathrm{MPa}$ \\
\cline { 2 - 3 } & Feedwater temperature & $99.6^{\circ} \mathrm{C}$ \\
\cline { 2 - 3 } & Feedwater flow rate & $4.37 \mathrm{~kg} / \mathrm{s}$ \\
\hline
\end{tabular}

and the natural circulation system. Table 1 shows the detailed design parameters of the REX-10.

\section{REX-10 System Model}

The REX-10 Model is composed of three parts, the first of which is the generation part. The REX-10 generates heat and electricity, but only the electrical simulations are being considered in the RTDS. The simulations based on heat generation are carried out in another part of the integrated system. The second part is the inner plant load, which is necessary to operate and maintain the REX-10 system. The last part is the emergency generation part, and a simple diesel generator is selected for the simulation [5]-[7].

In this model, the REX-10 is connected to a generation bus. Since the REX-10 supplies heat and electricity, it needs to be installed near the load center. If the REX-10 system is in an emergency condition, the inner plant load receives the electricity from the power grid module. In the emergency condition, the required electric power for the inner plant load is being supplied from the power system. If the power system is incapable of providing the required electricity, a diesel generator will be operated for such an emergency condition. In normal conditions, the diesel generator does not operate. If a problem arises in the nuclear power plant, the electricity would be supplied to the inner load through an emergency connection from the grid. If there is a problem in the emergency connection, a diesel generator starts to supply the electricity to the inner plant load. The electrical REX-10 module of the RTDS is shown in Fig. 3.

About $80 \%$ of the REX-10's output is used for heat load and $20 \%$ for power generation. In normal conditions, the REX-10 is operated as a base-load generator. However, unlike large nuclear power generators, the output of the REX-10 system can be controlled by changing the heatelectricity ratio. By controlling the steam amount, loadfollowing is somewhat possible.

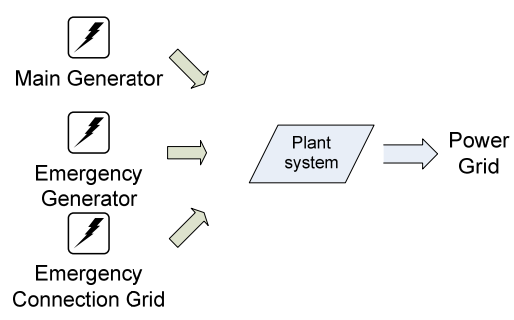

Fig. 2. Concept of the REX-10 system.

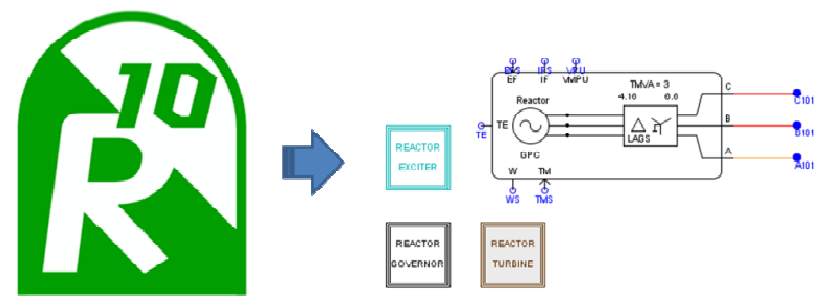

Fig. 3. Electrical REX-10 module in RTDS model. 


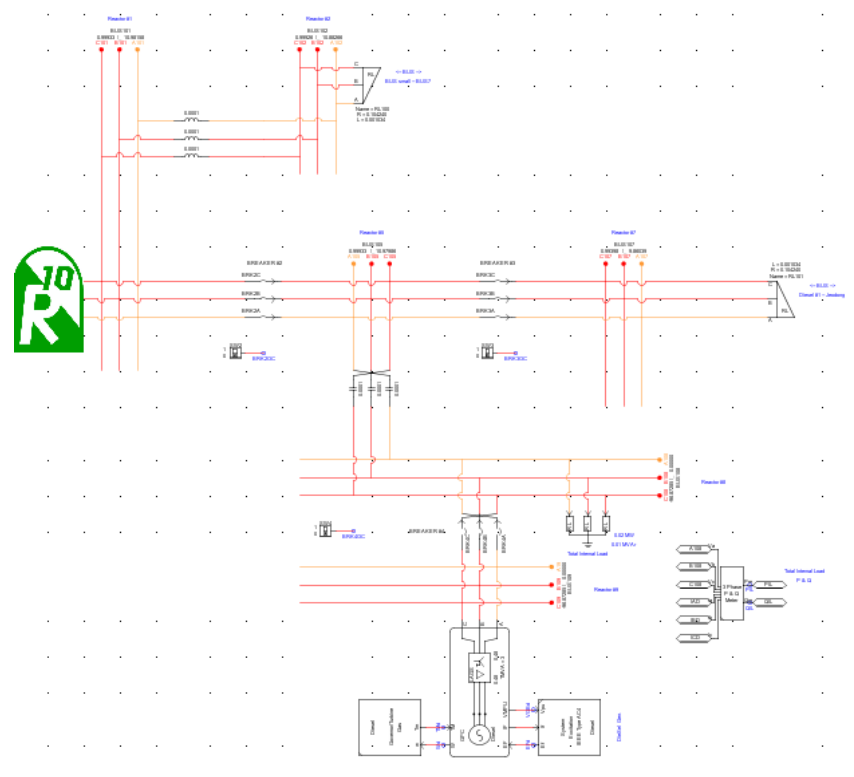

Fig. 4. REX-10 system in RTDS.

\section{SCADA System}

The SCADA system is a supervisor system for the control of power flow and the monitoring of the state of a regional energy system, and serves the role of data acquirement, processing and analysis. For the protection and monitoring of power systems, the SCADA system supervises the transmission and distribution facilities. The installed IEDs (Intelligent Electronic Devices) are used to acquire the data. In this paper, the real time digital simulator (RTDS) plays the role of the power system represented as the RTDS models. It is necessary to connect the RTDS to the SCADA system. The RTDS generates some simulation result data such as power, voltage and phase, which is used to control and monitor the SCADA and HMI system.

The composition of the SCADA simulator is as follows: Various information (current, voltage, power, watt-hour, frequency, power factor, operating state of the equipments) regarding the power equipment can be automatically monitored through the SCADA simulator's low level relays, and the relays' additional point of contact. The machine's states and measured values are displayed on the monitor, making it possible for the operator to control the whole power system by looking at the screen. Also, the changes in the state of the supervision point are logged and recorded for the management of the whole system by the operator. The data (measured value) is assorted, aggregated and calculated, and this sorted data according to time are used for management of the system. The protection relays, etc., are checked for their operational state and during a fault, and the fault details are displayed on the HMI screen using a symbol and an audio alarm perceivable by the operator.

Status monitoring is constructed so that each machine's operational state is supervised by providing the latest information to the HMI. For supervision, various types of measured data are necessary. The monitoring system is

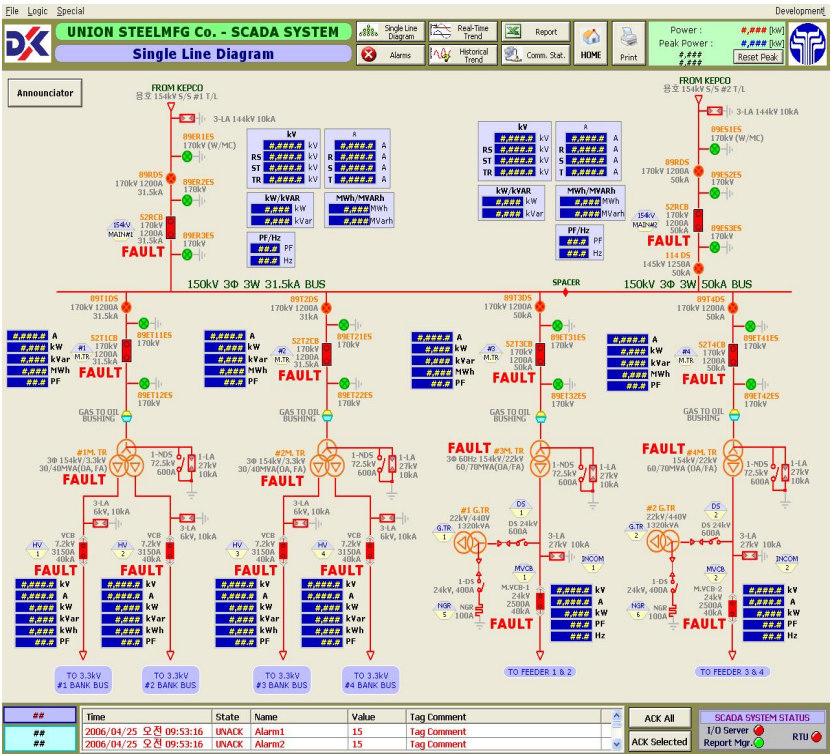

Fig. 5. Power monitoring HMI system.

able to collect the voltage (V-3phase/1phase), current (A3 phase/1phase), power $(\mathrm{kW})$, power factor $(\mathrm{PF})$, and frequency $(\mathrm{Hz})$ from the IED.

For the state indication, the data is classified into the measured value, operational state, alarm, etc., and is displayed on the screen. In order to indicate the present status, the important measured information should be displayed on the screen in real-time using line graphs.

Some alarm and event functions are shown in Fig. 7. Event functions are comprised of system events and alarm events. System process management, user log-in and logout are considered as system events, and alarm events are considered as faults in the system or the condition of communications. If trouble has occurred in the system, the alarm function would operate in real-time, allowing the operator to recognize the error.

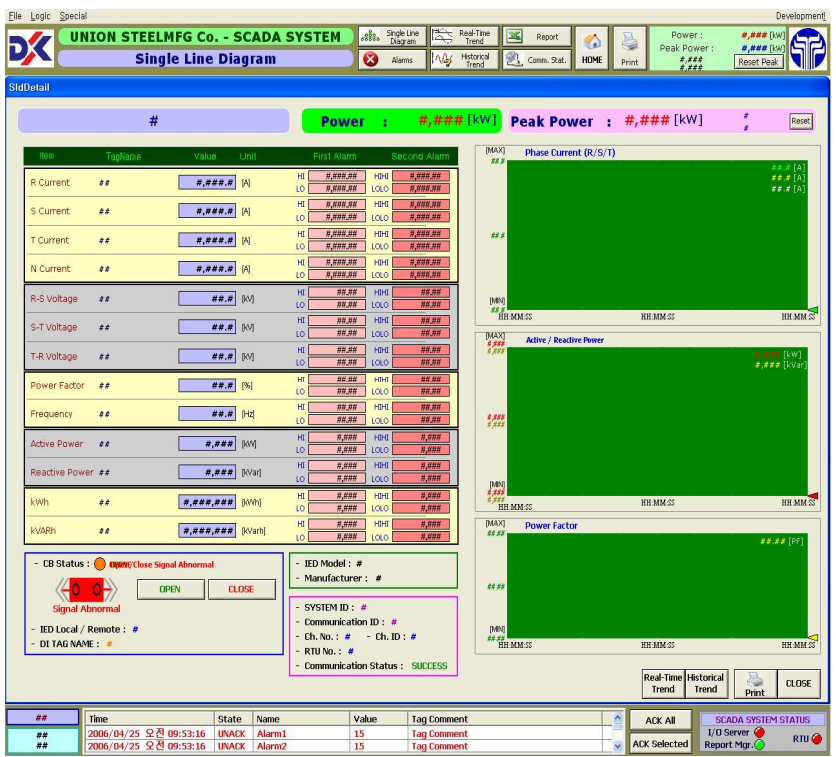

Fig. 6. Relay setting data in HMI system. 


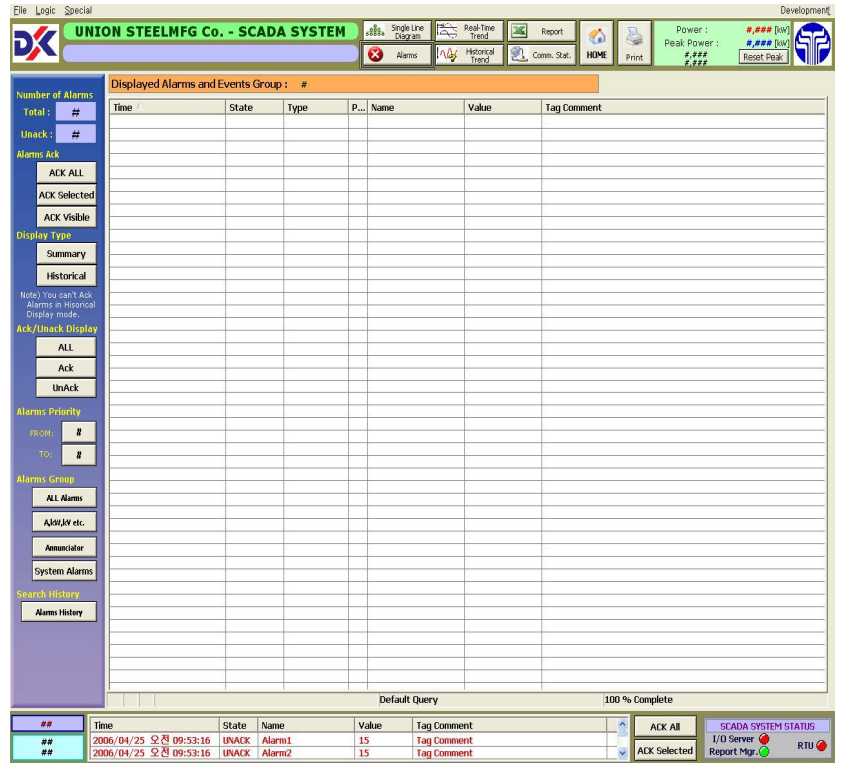

Fig. 7. Alarm and event function in HMI system.

For historical trends, the graph can be displayed for any day that the operator would like to see. The operator is able to execute this work by selecting the desired date from the calendar, which is designed to save daily 24-hour weather forecasts and to print the data in the form of a daily report. The monthly forecast must save the data for the whole month and then print it, according to the fixed format, in the form of a monthly report.

The HMI, the heart of the system, is comprised of the latest software and up to-date CPU, MEMORY, auxiliary memory, and other peripheral units. The HMI has the ability to process various functions in real-time, and the collected data and information from the external $\mathrm{I} / \mathrm{O}$ devices are analyzed and displayed on the screen.

In order to transfer the output data of the RTDS to the SCADA, an Analog Output card must be installed into the

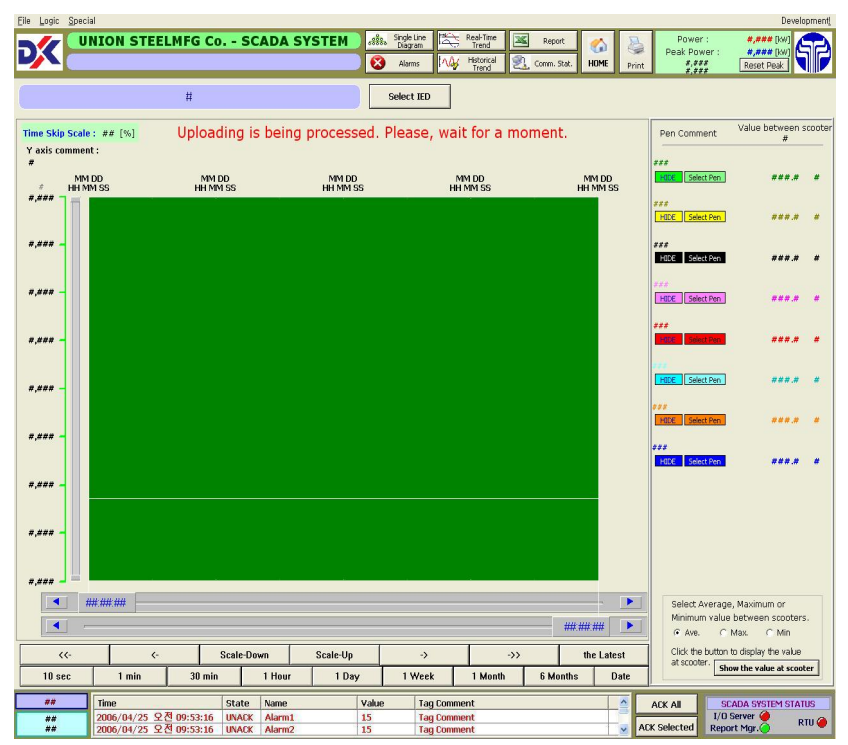

Fig. 8. Historical trend in HMI system.
RTDS and the voltage signal level should be adjusted to $\pm 10 \mathrm{~V}$. These signals are transferred to the SCADA through its Analog Input card. The analogue output component in the RTDS is shown in Fig. 10. This component is used to write signals to a twelve channel GTAO card connected to the processor card via an optical port. The values of each bus's active power, reactive power, phase angle and voltage are transferred and can be checked and controlled on the HMI's screen.

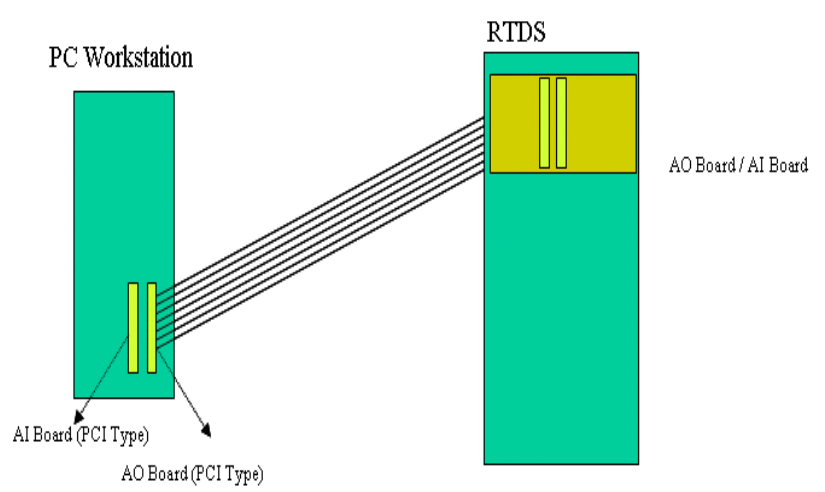

Fig. 9. Hardwiring between SCADA and RTDS.

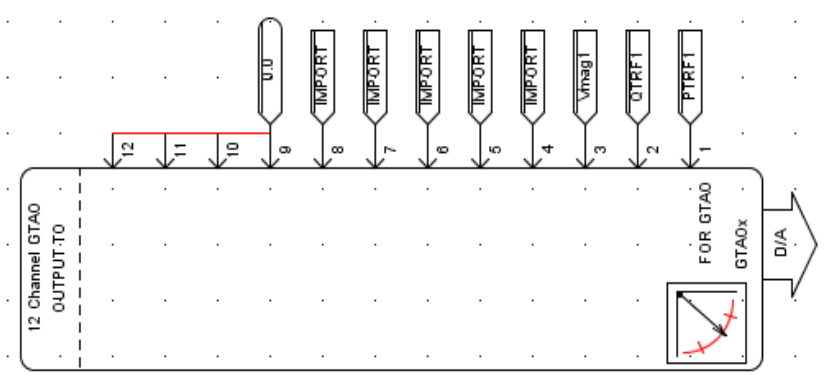

Fig. 10. Analogue output component in RTDS.

\section{System Configuration}

The data flow of the whole system is shown in Fig. 11. For the simulation, the RTDS is regarded as a power system. The electrical parts of REX-10 are implemented in the RTDS. The relay operates according to the simulation results and a system control can be applied using the HMI. The monitoring data of a specific area are visualized by the SCADA system. In order to reflect the heat demand, HER (heat-electricity ratio) should be controlled by the REX-10 remote control.

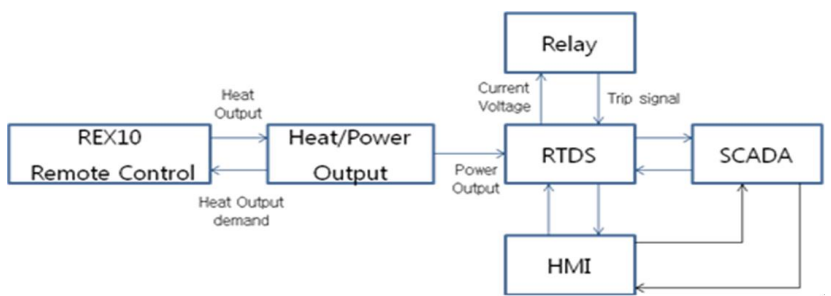

Fig. 11. Data flow of the proposed systems. 


\section{Conclusion}

This paper presented an integrated system which consists of a real-time simulator, a SCADA system, a small reactor, IEDs and an HMI system for a regional power system with a small nuclear reactor, the REX-10. The REX-10 system is used as a co-generation system to supply heat and electricity to the surrounding areas. Several simulation models were developed using the real time simulator, $\mathrm{RSCAD} / \mathrm{RTDS}$. The proposed system is used to validate the dynamic performance of the REX-10 system, and the SCADA system and an advanced HMI system are implemented to supervise a regional energy system.

\section{Acknowledgements}

This work was supported by a RERI \& KESRI project funded by MKE.

\section{References}

[1] Man-Gyun Na, Moo-Hwan Kim, Sang-Seung Lee and Doo-Jeong Lee, "Development of Regional Energy Reactor, REX-10," Proceedings of the 7th International Conference on Nuclear Option in Countries with Small and Medium Electricity Grids, Dubrovnik, Croatia, May 25-29, 2008.

[2] J. Kim, H. Joo, B. Jang, Y. Choi, M. Na, M. Kim and G. Park, "Thermal Hydraulic Research for Regional Energy Reactor," 16th Pacific Basin Nuclear Conference (16PBNC), Aomori, Japan, October 13-18 2008.

[3] Eckhard Shulz, "What's the importance of cogeneration," www.sealnet.org, April 2006.

[4] Gian Luigi Berta, Alessandro Pini Prato and Luca Garbarino "Design criteria for distributed cogeneration plants," Energy, Vol.31, Nos.10-11, pp.14031416, August 2006.

[5] Dong-Hee Yoon, Sea-Seung Oh, Seongil Hur and Gilsoo Jang, "Influence of small-scale reactors on power system dyna-mics," WMSCI2006 conference proceeding, Orlando, Florida, USA, July 16-19, 2006.

[6] "Real time digital simulator manual (RSCAD version)," RTDS technologies, September 2006.

[7] "Dynamic Models for Fossil Fuelled Steam Units on Power System Studies, Working Group on Prime Mover and Energy Supply Models for System Dynamic Performance Studies," Transactions on Power Systems, Vol.6, No.2, May 1991.

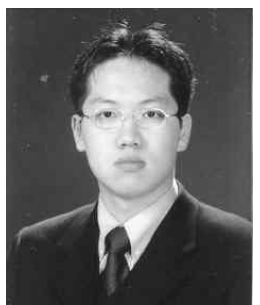

Hansang Lee He was born in Korea in 1980. He received his B.S. and M.S. degrees in electrical engineering from Korea University, Korea. He is currently pursuing his Ph.D. degree at Korea University graduate school. His research interests include railway systems, power quality, renewable generation, and energy

storage systems.

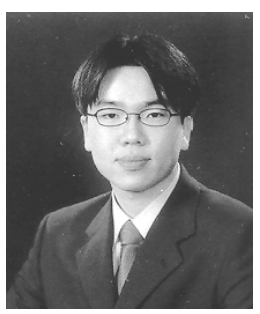

Dong-Hee Yoon He was born in Korea in 1981. He received his B.S. degree in electric engineering from Korea University, Korea. He is currently pursuing his Ph.D. degree at Korea University graduate school. His research interests include wind power systems, dispersed generation and HVDC systems.

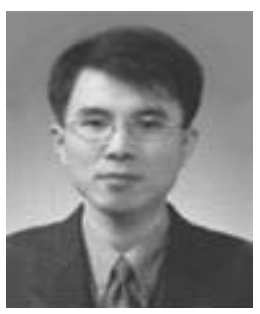

Gilsoo Jang He received his B.S. and M.S. degrees from Korea University, Korea. He received his Ph.D. degree from Iowa State University in $1997 . \mathrm{He}$ worked in the Electrical and Computer Engineering Department at Iowa State University as a Visiting Scientist for one year, and at Korea Electric Power Research Institute as a researcher for two years. He is presently an Assistant Professor at the School of Electrical Engineering at Korea University. His research interests include power quality and power system control.

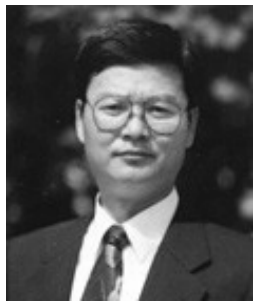

Jong-Keun Park He was born in Youseong, Chungcheongnam-Do, Republic of Korea, on October 21, 1952. He received his B.S. degree in Electrical Engineering from Seoul National University, Seoul, Korea in 1973 and his M.S.E.E. and Ph.D. degrees in Electrical Engineering from the University of Tokyo, Japan, in 1979 and 1982, respectively. He is currently a Professor at the School of Electrical and Computer Engineering, Seoul National University. He is a Fellow of the IEE and a Senior Member of the IEEE.

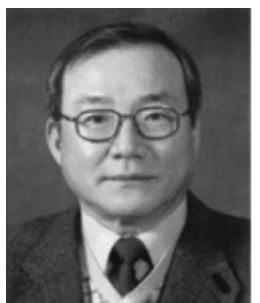

Goon-Cherl Park He was born in Busan, Korea on July 29, 1952. He received his B.S. and M.S. degrees in Nuclear Engineering from Seoul National University, Seoul, Korea, in 1975 and 1979, respectively, and his $\mathrm{Ph} . \mathrm{D}$. degree in Nuclear Engineering from Rensselaer Polytechnic Institute (RPI), USA, in 1983. Since 1983, he has been with the Department of Nuclear Engineering of 32-Dong, Seoul National University, Seoul, Korea, as a professor. His present research interests are two-phase flow, very high temperature gas cooled reactors, and nuclear district reactors. 